\title{
A promoção da saúde enquanto estratégia de prevenção ao uso das drogas
}

\author{
Health promotion as a strategy for the prevention of drug use
}

Fátima Büchele ${ }^{1}$

Elza Berger Salema Coelho ${ }^{1}$

Sheila Rubia Lindner ${ }^{2}$

${ }^{1}$ Departamento deSaúde Pública, Centro deCiências daSaúde, Universidade Federal deSanta Catarina. Campus Universitário, Trindade. 88010-970 Florianópolis $\mathrm{SC}$

buchele@mbox1.ufsc.br ${ }^{2}$ Secretaria deEstado da SaúdedeSantaCatarina.
Abstract This article addresses health promotion and prevention of drug use, reviewing approaches and conceptualizations without specifying determinate classes of drugs and their licitness or illicitness. The objective of this paper is to describe the prevention of drug useand to raise pertinent aspects of drug abuse for the construction of a health promotion strategy. As refers to drug use, Brazil has invested in the formulation of policies for health promotion, protection and recovery, however humanized, inter-sectorial, decentralized, integrated, democratic and active approaches need to be implemented. This review shows the need for more discussions about the prevention of drug use involving educators, parents and the community, in a structured multiple process integrating and involving institutions and sectors in the co-responsibility to promote the health of the population in this sense. This articlealso shows our concern with finding ways that contribute to the implementation of public policies as refers to drug addiction.

Key words Health promotion, Approaches to pre vention, U se of drugs
Resumo Esteartigo descrevea promoção da saúdee prevenção ao uso das drogas, revisando abordagens, conceituações, sem especificar sua classificação, se jam elas lícitas ou ilícitas. Tem como objetivo descrever a prevenção ao uso de drogas e levantar aspectos pertinentes ao uso indevido na construção de uma estratégia de promoção da saúde. A atenção sobre drogas no Brasil tem investido na formulação de políticas de promoção, proteção e recuperação da saúde; porém, enfoques mais humanizados, intersetoriais, descentralizado, democrático e participativo ne cessitam de implementações. Essa revisão mostra a necessidade de ampliar discussões sobre a promoção da saúdeea prevenção ao uso das drogas, envolvendo educadores, pais, comunidade, num processo estruturado composto de múltiplas facetas, que integre e comprometa instituições e setores na co-responsabilidade de promover e prevenir a saúde da população nestesentido. M ostra também nossa preocupação em percorrer caminhosquecontribuam para implementar políticas públicas na questão da drogadição.

Palavras- chave Promoção da saúde, Abordagens de prevenção, Drogas 
Introdução

Mudanças econômicas, políticas, sociais e culturais ocorreram no mundo nos últimos séculos, produzindo alterações significativas na vida das pessoas e na sociedade. Ao mesmo tempo, foram criadas tecnologias mais precisas e sofisticadas nas atividades humanas e 0 aumento dos desafios e dos impasses foram acrescentados no nosso viver.

A saúde, enquanto uma esfera da vida de homens e mulheres em toda sua diversidade e singularidade, passa por mudanças essenciais. " $\mathrm{O}$ processo de transformação da sociedade é também o processo de transformação da saúde e dos proble mas sanitários"1.

N essa perspectiva, a promoção da saúde é entendida enquanto processo, no qual indivíduos, comunidades e redes sociais compartilham seus conhecimentos com objetivos de juntos encontrar melhores condições de saúde numa contínua procura de direitose decidadania. Ela pretende trabaIhar com o desenvolvimento, com a participação e com a interação do ser humano no seu meio social, econômico, cultural, interagindo com as diversas instâncias nos diferentes níveis, como uma possibilidade concreta de ruptura de paradigma no campo da saúde, considerando a realidade objetiva da sociedade gl obalizada.

A promoção da saúde é associada a um conjunto devalores, tais como vida, solidariedade, eqüidade, democracia, cidadania, desenvolvimento, participação, parceira, entre outros. Refere-setambém a uma combinação de estratégias: do Estado buscando políticas públicas saudáveis, da comunidade nas ações comunitárias; dos indivíduos na busca de suas habilidades; do sistema de saúde reorientando-o, bem como deparceiras intersetoriais, com responsabilidade múltipla². "A promoção da saúde pretende ser um novo modo de compreender a saúde e a doença e um novo modo dos indivíduos e das coletividades obterem saúde ${ }^{3 " .}$.

Ela ainda é uma estratégia de articulação de produção de saúde no modo de pensar e de operar articulado às demais políticas e tecnologias desenvolvidas no sistema de saúde brasileiro, contribuindo na construção de ações que possibilitam responder às necessidades sociais em saúde.

No SUS, a estratégia de promoção da saúde é uma possibilidade de enfocar os aspectos que determinam o processo saúde-adoecimento em nosso país, tais como violência, desemprego, subemprego, falta de saneamento básico, habitação inadequada e/ou ausente, dificuldade de acesso à educação, fome, urbanização desordenada, qualidade do ar e da água, e potencializar formas mais am- plas de intervir em saúde e conseqüentemente no uso abusivo às drogas ${ }^{1}$.

Deste modo, promover significa dar impulso, fomentar, originar, gerar ${ }^{4}$. Lefevre ${ }^{3}$ refere que, para entendermos melhor a promoção da saúde, é necessário revisitar a doença e tornar mais claro 0 sentido de saúde que desejamos promover. "Isto porque saúde não é um conceito auto-explicável, nem óbvio, nem evidente; muito ao contrário".

Com base nessa temática, a preven ção se constituiu num esforço de se antecipar à doença, como 0 ato ou efeito de prevenir, de precaver, de chegar antes, de evitar al gum dano. É a disposição ou preparo antecipado, preventivo, ou o modo de ver antecipado. Prevenir, como o próprio nome diz, é também prever, não apenas impedir ${ }^{5}$.

A prevenção ao uso de drogas busca grupos específicos (crianças, adolescentes, comunidades, escolas), incentivando-os a buscarem seu desenvolvimento integral, através de vivências pessoais da vida humana. No caso específico ao uso das drogas, a finalidade dessas ações é atuar sobre fatores que predispõem o seu uso ou abuso, criando uma mentalidade de participar da dinâmica social de forma ativa e preventiva. Neste sentido, a prevenção fica reservada a medidas adotadas antes do surgimento ou agravamento da situação, visando a afastar ou diminuir a probabilidade de ocorrência de danos nos indivíduos ou na coletividade.

Diante desse cenário, o objetivo do presente artigo é descrever o tema promoção da saúde e prevenção ao uso de drogas, revisando algumas abordagens e conceituações, sem especificarmos uma determinada classificação de drogas, sejam elas lícitas ou ilícitas. Levantamos também aspectos pertinentes ao uso indevido de drogas na construção de uma estratégia de promoção da saúde e prevenção ao uso de drogas.

\section{Ações de prevenção ao uso de drogas}

O concei to de intervenção preventiva foi desenvolvido como resultado dos avanços no conhecimento científico. A prevenção ao uso de drogas visa a uma atitude responsável com relação a elas, levando em consideração que o uso de drogas é um problema pessoal, social, cultural, entretantosque permeiam esse tema.

Por muito tempo, pensou-se que, ao falar de prevenção do alcoolismo e/ou consumo de outras drogas, imediatamente a intervenção deveria ser desenvolvida dentro de escolas, fornecendo informações sobre 0 assunto. Num primeiro momento, pensou-se que informações úteis seriam aque- 
las que mostrassem os prejuízos causados pelo seu uso. Normalmente, os técnicos abordavam esses danos sem ao menos citar o lado relaxante elúdico que algumas drogas podem provocar quando usadas em doses moderadas.

Com a transformação do modelo socioeconômico de produção, aconteceram novos sistemas de comercialização e propagação. Produtos lícitos ou ilícitos conheceram outras formas de fabricação e ofertas, com novas possibilidades de busca por jovens e adultos.

De acordo com cada meio social, existem diferentes tipos de drogas. Existem fatores de risco para o início do uso de drogas, que são descritos por $M$ aluf e $M$ eyer ${ }^{6}$ como os relacionados ao ambiente familiar, a falta de vínculos afetivos, a dificuldade para resistir à oferta de drogas, ao uso de drogas tolerado pelo ambiente que o circunda, a falta de regras clara sobre o uso, entre outros.

Associado a esses fatores, são veiculadas nos meios de comunicação do Brasil campanhas preventivas, intituladas "drogas nem morto", em que são abordadas drogas ilícitas. Ao mesmo tempo, drogas lícitas, tais como álcool etabaco, responsáveis por gravíssimos problemas de saúde pública, aparecem através dos mesmos meios, apresentando propagandas enfáticas e bem elaboradas, sem ser considerado nem discutido a séria dependência, o custo social, o sofrimento pessoal e familiar que podem causar, quando usadas em excesso.

Cada vez é mais importante cuidar da vida, reduzindo vulnerabilidades que levam ao adoecer. No entanto, enquanto se valoriza a qualidade de vida, a alimentação saudável, a vida sem drogas, "drogas nem morto", o consumo de drogas lícitas é presente no cotidiano, como podemos identificar ao assistirmos diariamente à tel evisão, nos programas considerados populares, nos que ensinam a degustar vinhos, nas novelas, entre outros. Esse movimento evidencia um clima social de aceitação desse consumo e traz uma mensagem de que 0 beber, por exemplo, integra o ritual das comemorações. U ma mensagem que, na maioria das vezes, atinge diretamente os jovens. Os recursos da mídia vêm sendo pouco estudados e explorados como instrumentos de prevenção e, portanto, merecem maior atenção, uma vez que a utilização de tais recursos, aliada a outras medidas de prevenção, pode representar uma interessante alternativa a ser considerada 7 .

As estratégias vinculadas à recuperação da saúde implicam um custo significativamente al to, tanto em termos financeiros quanto de recursos humanos. A análise do processo saúde-adoecimento evidenciou que a saúde é resultado dos modos de organização da produção, do trabal ho eda sociedade em determinado contexto histórico. Na medida em que se compreendeu o processo saúde-adoecimento como determinado pela existência e condições de trabalho, qualidade de moradia, de alimentação e do meio ambiente, possibilidades de lazer, graus de autonomia e exercício da cidadania, dentre outras construções sócio-históricas, foi preciso criar outro modo de pensar as políticas e ações sanitárias ${ }^{1}$. 0 desenvolvimento das tecnologias biomédicas e da qualidade dos medicamentos produziu intervenções com grandeeficiência eeficácia para o tratamento de situações graves de adoecimento.

Nesta perspectiva, o M inistério da Educação estabeleceu princípios norteadores para o desenvolvimento de ações preventivas, baseando-se em diretrizes de política educacional de prevenção ao uso de drogas 8 . Esses princípios dizem respeito às programações preventivas que devem considerar os contextos histórico, sociocultural e econômico nos quais se insere a população-alvo, bem como 0 conhecimento objetivo da realidade do consumo e das motivações quea sustentam. A prevenção deve levar em consideração as estruturas sistêmicas dos estados e municípios, bem como a organização curricular das escolas e as ações humanas nelas vivenciadas.

Contudo, antes de estabelecermos programas preventivos, é imprescindível procedermos a um diagnóstico da situação do consumo de drogas nas comunidades, nas escolas, entre outras. A educação preventiva deveser integrada a outros programas educacionais e considerar os programas sociaise de saúde, delimitando claramente suas ações.

Entendemos que problemas relacionados à questão da drogadição devem ser abordados numa concepção ampla, considerando aspectos bio-psico-socioculturais, direcionando-os para ações de promoção da saúde, valorização da qualidade de vida, buscando assim o equilíbrio do homem no meio ambiente, visando à ampliação dos compromissos sociais, do indivíduo em relação a si, ao outro e à comunidade.

As drogas representam um agressor entre tantos outros presentes na vida moderna. Seu uso não representa um processo de alienação social, mas sim, um dos fatores que prejudicam, alienam, embriagam a formação dos jovens e até das crianças, como vem sendo identificado atualmente?.

A ação educacional poderia prover-se de dados da realidade para possibilitar correlações profundas e integradoras, nas quais as intervenções de pessoas estranhas ao cotidiano escolar fossem evitadas, por serem episódicas e sem continuidade. 0 planejamento ea implantação de programas 
preventivos devem contar com a adesão de todos os níveis do sistema educacional. Ações de promoção da saúde deveriam permear de forma sistemática todo o currículo escolar, valorizando o professor como mediador do processo, fazendo-o atuar como um interlocutor privilegiado do educando e capacitando-o com treinamentos específicos para enfrentar a questão com objetividade, sem medo, sem alarde.

0 êxito da atividade do professor no processo depende de que ele absorva perfeitamente a filosofia e os objetivos visados, identificando-os como um verdadeiro promotor da saúde e da prevenção específica.

$\mathrm{Na}$ concepção de valorização da qualidade de vida, é importante evitar a "pedagogia do terror" ou a "pedagogia pelo susto", bem como os procedimentos deamedrontamento e intimidação, pautados na exacerbação das advertências sobre perigos advindos do consumo de drogas. Outrossim, não podemos desconsiderar esse tipo de pedagogia, considerando que mesmo os países sociaisdemocratas, com grande qualidade de vida, utilizando metodologias mais construtivistas, Iançam mão dessa metodologia quando querem chamar aten ção para um grande problema de impacto na população, no qual estratégias utilizadas para pre venção não se mostram eficazes ${ }^{5}$.

N esta perspectiva, são necessários investimentos que valorizem a escola e seus profissionais, de vendo ser passíveis deavaliação. Contudo, isto pre cisa ser considerado prioridade nas ações governamentais, ou seja, que propostas interinstitucionais eintersetoriais estejam incorporadas aosinteresses prioritários destas ações.

0 desconhecimento técnico e a maneira como étratado o uso indevido de drogas dificultam promover saúde e prevenir seu uso, o que nos leva a pensar em revermos os atuais model os de prevenção e ampliarmos nossas discussões, na tentativa dereverter model os instituídos eformalmente propostos.

Ramos $^{10}$ afirma que 0 campo das drogas mais do que qualquer outro exige que levemos em consideração o binômio que determina as regras do mercado: a oferta e a procura. Dados nacionais dos últimos dez anos demonstram que o consumo está ascendente, o que nos faz questionar a eficácia das medidas governamentais. Fruto de uma perversão do sistema, a medida adotada mais consistente tem sido a repressão da droga ilícita sem intervenções quanto às drogas lícitas e muito menos estratégias preventivas que visem a diminuir a demanda do consumo de substâncias psicoativas?.
Alguns programas se baseiam na idéia de quea forma mais segura de prevenção é nunca experimentar, como se esta estratégia pudesse frear a curiosidade perante o novo, tão comum aos jovens, além de não oferecer subsídios efetivos para que resistam às pressões sociais neste sentido. Outros programas estimulam e dão subsídios aos professores a darem apoio afetivo aos jovens para que eles enfrentem as dificuldades em vez de fugirem delas ${ }^{11}$.

Em termos da finalidade essencial de educação preventiva frenteàs drogas, parecequejá vem ocorrendo uma evolução nas medidas preventivas em muitos países. Primeiramente, esse processo preventivo reduzia-se à exortação de "não se aproxime" das drogas. Esta ainda é a meta explícita de muitos programas. A experiência parece mostrar hoje a inutilidade deste objetivo, principalmente nas sociedades que não impõem nenhuma restrição ao consumo de álcool e fumo ${ }^{12}$. Da mesma forma, reprimir e assustar com muita informação não funciona. Este processo é restrito, pois os modelos de atenção baseados em práticas repressivas, ou na criminalização excessiva, sugerindo somente ao usuário "não use drogas", "tenha medo das drogas", não facilita a atuação nos níveis preventivos e de tratamento ${ }^{13}$.

As atividades preventivas referentes às drogas, quando denatureza factual, com credibilidadejunto à comunidade-alvo, favorecem vínculos positivos, oportunizam espaços para reflexão, trocas de experiências eestimulam o exercício da cidadania e solidariedade ${ }^{10}$.

"Contrapondo-se a essa postura centrada na repressão, pesquisadores eagentes de saúde defendem a idéia de desenvolver ações preventivas comprometidas com a saúde da coletividade, a partir do ponto de vista dos grupos mais atingidos pelo uso de drogas ${ }^{14 "}$. Diante dessas considerações, é evidente que estratégias de promoção da saúde, prevenção ao uso de drogas sugerem estreita vinculação, sendo umas complementares as outras.

\section{Abordagens relacionadas à prevenção do uso de drogas}

Informar por informar pode causar mais mal do que bem, assinala o relatório da Iugoslávia. $\mathrm{Na}$ N oruega, um estudo sobre as atitudes dos educadores mostrou que, na opinião destes, a informação por si só não fornecia elementos suficientes para fundamentar as escolhas individuais em termos de drogas. 0 relatório da Austrália declara que se considera que a informação tem uma con- 
tribuição essencial no sentido de se atingir o objetivo da educação relativa às drogas, mas ela não é suficiente para modificar as atitudes e os comportamentos. A maioria de outros relatórios contém observações no mesmo sentido ${ }^{15}$.

Apesar desses resultados já terem sido divulgados, algumas autoridades da área acreditam, ingenuamente, que fornecer informações aos jovens não vai despertar sua curiosidade em experimentar drogas. Torna-se difícil que comportamentos possam alterar-se em função de informações veiculadas pela mídia, cartazes ou folders distribuídos em escolas e/ou comunidade, quando riscos da perda das relações afetivas, da liberdade, saúde e segurança não são suficientes para tal ${ }^{16}$.

0 consumo de algumas drogas, sobretudo maconha e cocaína, cresceu bastante ao longo da última década. Essa constatação sugere a necessidade da implementação de alternativas preventivas ainda pouco exploradas ${ }^{17}$.

Geralmente, pensamosque mudanças comportamentais seriam decorrentes de mudanças de atitudes e estas, por sua vez, tributárias de alterações no âmbito dos conhecimentos. A al teração de comportamento pode ocorrer a partir da influência de pessoas e determina mudanças de atitudes e comportamentos.

Instâncias oficiais brasileiras, como o Ministé rio da Educação, através da Secretaria de Projetos Educacionais Especiais, distingue seis abordagens principais para a prevenção do uso de drogas no Brasil, acrescentando seus pontos críticos, ou seja5:

1. Enfoque do princípio moral: apela à condenação do uso de drogas em função de pressupostos religiosos, morais ou éticos. Invoca valores como patriotismo ou sacrifício pelo bem comum;

2. Amedrontamento: baseia-se em campanhas informativas sobre os aspectos negativos das drogas, e com o intuito de persuadir os jovens a evitálas. Inspirada na "pedagogia do terror", é a mais comumente utilizada na atualidade; mostra-se pouco eficaz por não mobilizar ajuventudeno sentido desejado e por ter pouca credibilidade face à experiência com drogas no cotidiano;

3. Conhecimento científico: proposto em oposição ao amedrontamento, transmitindo informações de modo imparcial e objetivo para que o educando possa tomar decisões racionais sobre o uso ou não de drogas. Porém, avaliações ${ }^{7}$ dizem que 0 aumento do conhecimento sobre drogas não se traduz automaticamente em uma diminuição do consumo, pois, em si, não muda as atitudes frente às drogas. Este modelo, não obstante, é utilizado para auxiliar o programa educativo mais amplo;

4. Educação afetiva: visa a modificar os fatores de personalidade que podem predispor ao uso de drogas. Com técnicas apropriadas, propõe desenvolver a auto-estima, a capacidade de lidar com tensões, frustrações e angústias, a habilidade de decidir einteragir em grupo, a comunicação verbal e expressão não verbal e a capacidade de resistir a pressões. As avaliações destacam a dificuldade de implementar tais programas nas escolas, por eles exigirem treinamentos especiais dos profissionais e disposição interna para acatar mudanças pedagógicas e de comportamento;

5. Pressão positiva do grupo: tenta mobilizar líderes naturais dos jovens para que assumam atitudes antidrogas nas atividades corriqueiras das diversas faixas etárias. Espera-se, deste modo, que a coesão afetiva dos próprios jovens forme organizações de solidariedade e auto-ajuda, afastando as drogas da convivência cotidiana ou, ao menos, desestimulando seu uso;

6. Q ualidade de vida: pretende promover estilos de vida saudáveis para barrar a procura por drogas. Adota um enfoque ecológico-ambiental e humano, no qual as drogas são discutidas en quanto agressores a uma vida saudável, tais como poluição, barulho, trânsito, violência, miséria, desemprego, injustiça social, entre outros. As experiências que abordam a questão da droga de forma integral tendem a ser ações mais articuladas, resgatando a cidadania individual e comunitária, bem como aspectos emergidos com o desenvolvimento dos trabalhos.

Esses pressupostos são, na verdade, modelos de ações para diminuição dos riscos e dos danos. Também é possível discutir temas mais gerais, como poluição, trânsito ou perigo atômico, por exemplo, pois esse modelo pretende não só a formação de um cidadão consciente da sua realidade e dos riscos existentes no mundo que o cerca, mas que tenha capacidade de escolher uma vida mais saudável para si e para sua comunidade.

Abordando concepções baseadas em aspectos mais saudáveis de viver, o Projeto Axé, desenvolvido na Bahia, Brasil, é uma experiência exitosa. Apesar de não enfocar diretamente a questão das drogas, tem uma grande virtude em ensinar jovens negros, pobres e marginalizados a não terem vergonha de suas origens. Esta proposta é considerada como prevenção em sentido mais amplo, pois podem e devem ser repetidas em outros os estados e países que desejam trabalhar com prevenção. A sociedade brasilei ra precisa aprender com elas e os profissionais de saúde e educação devem tirar proveito de ações tão consistentes e bem articuladas ${ }^{5}$.

Essa revisão sugere que não faltam princípios ou modelos de promoção da saúde para que ações 
preventivas relacionadas ao uso de drogas aconteçam. É evidente que não existe uma só faceta de atuação para desenvolvêlas; porém, sabemos que essas intervenções exigem formação, capacitação e consciência. Vivenciamos uma situação grave que abrange muitas esferas da nossa sociedade. N esse sentido, é importante, além de estarmos cientes dessas dificuldades, iniciarmos um movimento de atuação e sensibilização da problemática.

\section{Algumas considerações}

A educação sobre drogas deve ser um processo estruturado, que pode ser definido por instâncias oficiais na tentativa de ajudar indivíduos a aprender a desenvolver habilidades e atitudes frente ao uso de drogas. A promoção da saúde é uma importanteresposta como estratégia de enfrentamento dos problemas relacionados ao meio ambiente, à urbanização, à segurança alimentar e nutricional, ao desemprego, à moradia, ao uso de drogas lícitas eilícitas, entre outros ${ }^{18}$.

Os modelos preventivos são suficientemente amplos e vagos, em termos de visualização de re sultados, de tal forma que a adoção de um deles não necessita excluir ou copiar outros, mas sim integrá- los. $^{2}$ U $\mathrm{m}$ consenso sobre os processos utilizados para atingir objetivos propostos varia conforme cada situação e localidade a qual se destina a ação. Programas preventivos tornam-se mais efetivos se compostos de múltiplas abordagens, visando à integração deinstituições esetores. Os programas específicos de prevenção ao uso de drogas dependem das necessidades percebidas entre educadores, pais, crianças e jovens da comunidade. A promoção da saúde deve estar voltada à realidade comunitária, respeitando o direito de cidadania das pessoas, considerando o conceito ampliado de saúde, a necessidade de criar políticas públicas, a participação social na construção do sistema. É importante ressaltar a impossibilidade de alguns setores responderem sozinhos às transformações dos de terminantes econdicionantes da população, por isso a importância da integração entre eles.

As intervenções, por sua vez, devem voltar-sea comunidades pequenas eespecíficas, com planejamento local, avaliação e transparência. Constatase em al guns relatórios ${ }^{12}$ uma orientação no sentido de que a informação não pode ser eliminada dos programas e sim que deva ser considerada como um dentre numerosos componentes da educação sobre o uso de drogas. Essa informação está sendo cada vez mais englobada naquilo que alguns relatórios denominam de educação afetiva, caracterizando-a como de caráter mais integral e dirigindo-se ao conjunto da personalidade e não apenas a aspectos cognitivos ou intelectuais.

Nesse sentido, o direcionamento das questões relacionadas ao uso de drogas será efetivo se existirem alianças consistentes e prioritárias entre ações de poderes públicos, privados e comunitários, compondo redes de compromisso e co-responsabilidadequanto à qualidade devida da população, em que todos sejam participantes no cuidado com a vida.

São inúmeras as divergências que envolvem a questão da promoção da Saúde e da prevenção ao uso de drogas no Brasil. Os órgãos governamentais, na maioria das vezes, atuam isoladamente e dificilmente conseguem traduzir suas propostas em ações práticas. São relativamentefreqüentes os discursos políticos, as palestras, os simpósios e, até mesmo, os encontros científicos sobreo tema, mas são poucas as intervenções preventivas implementadas de fato. As poucas propostas governamentais que conseguiram atingir um estágio mais avançado de implementação ficaram fragilizadas no processo de mudança de governo, ou até mesmo acabaram sendo totalmente substituídas sem qualquer fundamento científico, como, por exemplo, 0 Projeto Valorização da Vida (Rio Grande do Sul) e o Projeto Escola é Vida (São Paulo). "No entanto, parece estar em curso um processo de mudança nesse contexto, uma vez que o número ea qualidade das intervenções vêm aumentando, ainda que discretamente, ao longo dos últimos anos ${ }^{19 "}$.

Diante das questões aqui discutidas, somos intimados a pensar em termos de construção de novos paradigmas e modelos de construção de conhecimentos relacionados à promoção da saúde e prevenção ao uso de drogas. Essa complexidade nos faz refletir no sentido de compreender melhor nosso meio.

É inegável que a questão da drogadição, atualmente, passa por uma crise talvez nunca assistida na nossa história. Ela não está separada da crise da saúde, no seu aspecto epistemológico, teórico e metodológico. Os fenômenos estão aí e nossa preocupação deve partir de uma visão preferencialmente construtivista, percorrendo caminhos que contribuam para implementar políticas públicas na questão da drogadição. 


\section{Colaboradores}

F Büchele participou das etapas do trabalho e foi responsável pela concepção teórica, estruturação metodológica e revisão final do manuscrito; EBS Coelho eSR Lindner participaram do levantamento bibliográfico e da revisão crítica da versão a ser publicada.

\section{Referências}

1. Brasil. Ministério da Saúde. Política Nacional de Promoção da Saúde - Documento Preliminar. Brasília: M inistério da Saúde; 2005.

2. Buss PM. U ma introdução ao conceito de promoção da saúde. In: Czeresnia D, Freitas CM, organizadores. Promoção da Saúde: conceitos, reflexões, tendências. Rio de Janeiro: Fiocruz; 2003. p.174

3. Lefevre F, Lefevre AM C. Promoção de saúde: a negação da negação. Rio de Janeiro: Vieira e Lent; 2004.

4. Brasil. M inistério da Saúde. N ormas e procedimentos na abordagem do alcoolismo. Brasília: M inistério da Saúde; 1994.

5. Brasil. Ministério da Educação. Programa Valorização da Vida. Proposta para uma política nacional de prevenção do consumo do álcool, tabaco e outras substâncias psicoativas. Braślia: M inistério da Educação; 1990.

6. Maluf DP, M eyer M. $O$ que preciso saber para fazer prevenção. In: Maluf DP, Takey EE, Humberg LV, M eyer M SC, Laranjo TH M. Drogas: prevenção e tratamento - o que você queria saber e não tinha a quem perguntar. São Paulo: Editora CLA; 2002.

7. Noto AR, Baptista MC, Faria ST, Nappo SA, Galduróz JCF, Carlini EA. Drogas e saúde na imprensa brasileira: uma análise de artigos publicados em jornais e revistas. Cad Saúde Pública [periódico na Internet] 2003 [acessado 2006 out 26]; 19(1):[cerca de 11 p.]. Disponível em: http://www.scielo.br/scielo.php

8. Correio da Unesco. Educação preventiva contra as drogas. Genebra: OM S; s/d.

9. Carlini EA, Galduróz JC, N oto AR, Nappo SA. I levantamento domiciliar sobre o uso de drogas psicotrópicas no Brasil: estudo envolvendo as 107 maiores cidades do país - 2001. São Paulo: CEBRID/UNIFESP; 2002.

10. Ramos SP, Plass AM, Cardoso NA. U so de drogas na adolescência: prevenção e tratamento. Porto Alegre: M ercado Aberto; 1999.

11. Labigalini JR, Eliseu J. Grupos Ajudam a Recuperar Dependentes. Estado de São Paulo 1998; 26 mai.
12. Monteiro S, Rebello S, Schall V. Jogando e aprendendo a viver: uma abordagem da aids e das drogas através de recursos educativos. In: M esquista F. D rogas e aids: estratégias de redução de danos. São Paulo: Hucitec; 1994.

13. M arlatt BC. Uso de drogas psicotrópicas no Brasil. In: Secretaria Nacional Antidrogas. Formação de multiplicadores de informações preventivas sobre drogas. Florianópolis: Gráfica LED/UFSC/SENAD; 2002. p. 65-83.

14. Contrim BC. Prevenção ao uso de drogas na escola. In: Seidl EM F, organizadora. Prevenção ao uso indevido de drogas: diga sim à vida. Brasília: CEAD/UnB/ SENAD/SGL/PR; 1999.

15. Olievenstein C. Em defesa da subjetividade nas campanhas de prevenção. Rev. Mind. 1997; 2(9).

16. Woodak $A$, Jarlais $D$. Das estratégias para a prevenção da infecção pelo HIV entre usuários de drogas e destes para seus parceiros. In.: M esquita F, Bastos F. D rogas e aids: estratégias de redução de danos. São PauIo: Hucitec; 1994.

17. Carlini EA, Galduroz JCF, Noto AR, Nappo AS, Lima E, Adiala JC. Perfil de uso da cocaína no Brasil. Jornal Brasileiro de Psiquiatria 1995; 44:287-303.

18. Campos GW, Barros RB, Castro AM . Avaliação de política nacional de promoção da saúde. Cien Saude Colet [periódico na Internet] 2004 [acessado 2006 out 2]; 9(3). Disponível em: http://www.scielo.br/scielo.php

19. Noto AR, Galduróz JCF. $O$ uso de drogas psicotrópicas e a prevenção no Brasil. Cien Saude Colet [periódico na Internet] 1999 [acessado 2006 out 2]; 4(1):[cerca de 7 p.]. Disponível em: http://www.scielo.br/scielo.php

Artigo apresentado em 19/05/2006

Aprovado em 11/09/2006

Versão final apresentada em 14/11/2006 